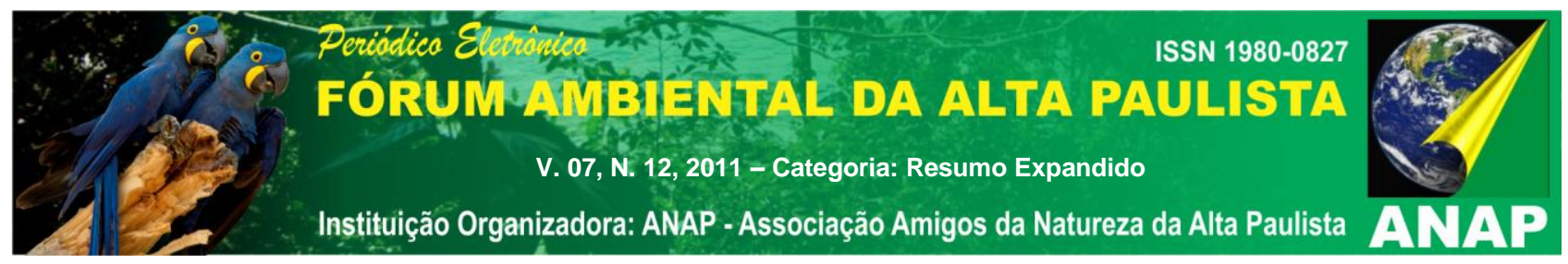

\title{
APLICAÇÃO DO COAGULANTE QUITOSANA NO TRATAMENTO DE CHORUME
}

Nome do Autor (a) Principal

Vitor Amigo Vive

Nome (s) do Co-autor (a) (s)

Taylla Evellyn Scapim Yamaguchi

Nome (s) do Orientador (a) (s)

Profa. Dra. Maria Cristina Rizk

Instituição ou Empresa

Universidade Estadual Paulista - FCT/UNESP

Instituição (s) de Fomento

$\mathrm{PIBIC/CNPq}$

E-mail de contato

vitorvive@hotmail.com

Palavras-chave

coagulantes naturais; chorume; tratamento

\section{INTRODUÇÃO}

Os altos padrões de consumo dos dias atuais vêm agravando a situação da disposição final dos resíduos sólidos urbanos (RSU), cuja decomposição dá origem ao objeto de estudo deste trabalho: o líquido percolado, proveniente da decomposição de resíduos orgânicos a partir de processos físicos, químicos e biológicos, comumente 


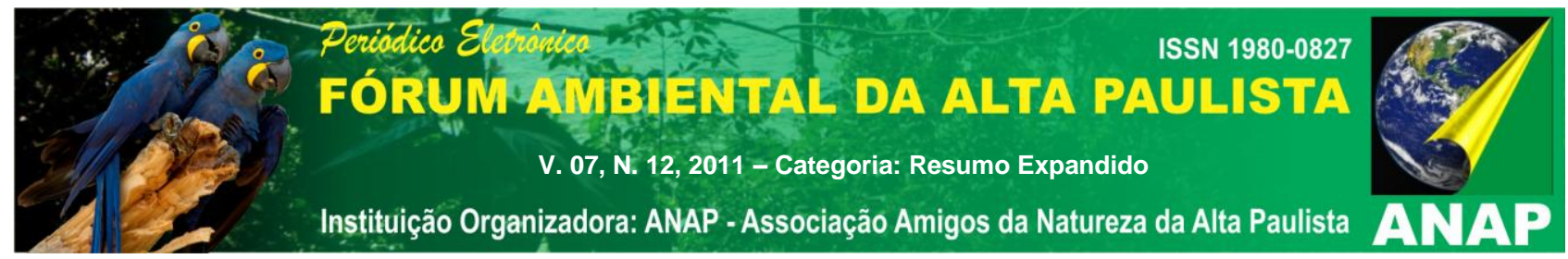

chamado de chorume, cuja composição costuma apresentar valores de $\mathrm{pH}$ mais baixos em aterros jovens e, valores mais altos em aterros maduros (Nagashima, 2009).

Vários processos de tratamento do chorume vêm sendo estudados atualmente, dentre eles citam-se os processos físico-químicos de coagulação, floculação e sedimentação com coagulantes naturais.

Os coagulantes naturais, em relação aos coagulantes químicos (mais utilizados para esta função), apresentam a vantagem de gerar menor quantidade de lodo, são biodegradáveis e não tóxicos (Madrona, 2010). Entre os principais coagulantes naturais estudados podem-se citar a Moringa oleifera, tanino vegetal e quitosana.

O biopolímero quitosana, único polieletrólito catiônico natural conhecido, tem sido utilizado como coagulante e floculante em sistemas aquosos, bem como polieletrólito auxiliar aos agentes coagulantes convencionais. A presença de grupos amino nas cadeias poliméricas permite que a quitosana atue como polieletrólito catiônico em $\mathrm{pH}$ menor que 6,5 e apresente uma alta densidade de cargas, que se adsorvem facilmente nas superfícies carregadas negativamente (Kimura, 2001).

A quitosana pode ser utilizada, com boa eficiência, como agente coagulante e floculante em tratamento de águas, formando menor quantidade de lodo que no tratamento convencional com sulfato de alumínio. Ainda, possui a vantagem de formar um lodo orgânico biodegradável, não tóxico e que pode ser disposto em aterro sanitário comum. Como a quitosana é efetiva na coagulação, nenhuma desvantagem é conhecida, podendo ser uma substituta promissora dos produtos sintéticos (Kawamura et al., 1993).

No que tange ao uso de quitosana no tratamento de efluentes, poucos estudos até o momento foram realizados, entretanto como a mesma apresenta bons resultados no tratamento de água, o presente estudo pretende investigar a aplicação do coagulante natural quitosana no tratamento de chorume.

\section{OBJETIVO GERAL}

O objetivo geral deste estudo é avaliar a eficiência de remoção de demanda química de oxigênio (DQO) e cor do chorume tratado por coagulação, floculação e sedimentação utilizando o coagulante natural quitosana. 


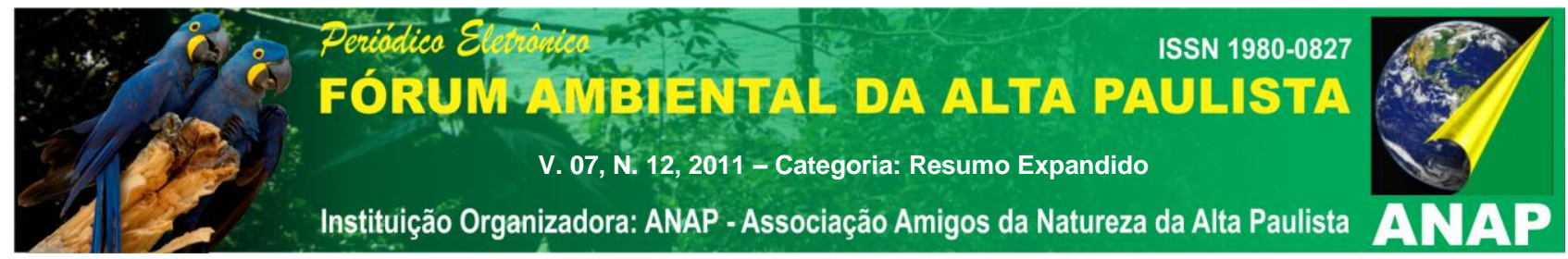

\section{OBJETIVO ESPECÍFICO}

Os objetivos específicos do estudo são a caracterização do chorume gerado no aterro controlado de Presidente Prudente/SP, bem como a determinação dos valores ótimos de $\mathrm{pH}$ e de concentração de quitosana utilizados, tendo como variáveis de resposta cor aparente e DQO.

\section{METODOLOGIA}

O chorume utilizado neste estudo foi coletado em março de 2011 no aterro controlado de Presidente Prudente/SP, na única lagoa (natural) existente no local. As amostras foram armazenadas em galões de polietileno, de cinco litros cada, a temperaturas abaixo de $10^{\circ} \mathrm{C}$.

Os ensaios de coagulação, floculação e sedimentação foram realizados em aparelho jar test, de seis provas, com regulador de rotação das hastes misturadoras. Utilizaram-se béqueres de polietileno de $1000 \mathrm{~mL}$, nos quais foram colocados $500 \mathrm{~mL}$ de chorume in natura. Os ensaios foram realizados a temperatura ambiente.

$\mathrm{O}$ ajuste de $\mathrm{pH}$ do lixiviado bruto foi feito com solução de ácido clorídrico $(\mathrm{HCl})$ ou hidróxido de sódio $(\mathrm{NaOH})$, quando necessário. $\mathrm{O} \mathrm{pH}$ foi determinado pelo método potenciométrico com auxílio de um pHmetro da marca HANNA ${ }^{\circledR}$ modelo $\mathrm{HI} 254$, previamente calibrado com soluções tampão de $\mathrm{pH} 4,0$ e 7,0. As faixas de $\mathrm{pH}$ e dosagem de coagulante foram baseadas no trabalho de tratamento de vinhaça de Girardi (2009), onde foi observada uma boa ação deste coagulante em baixos valores de $\mathrm{pH}$ (em torno de 4,0). Inicialmente, testou-se a quitosana em solução ácida (soluções de 2 e $4 \%$ ), porém, como não foram obtidos resultados satisfatórios, optou-se por sua utilização em pó, uma vez que soluções mais concentradas se tornariam inviáveis de manusear, em função da alta viscosidade da quitosana em solução. Com isso, adicionou-se ao chorume a quantidade de quitosana correspondente à concentração de $4 \%$ e as faixas testadas foram 0,4, 0,8 e 1,2 g/L. Os valores de $\mathrm{pH}$ testados foram de 3,0, 4,0 e 5,0. 


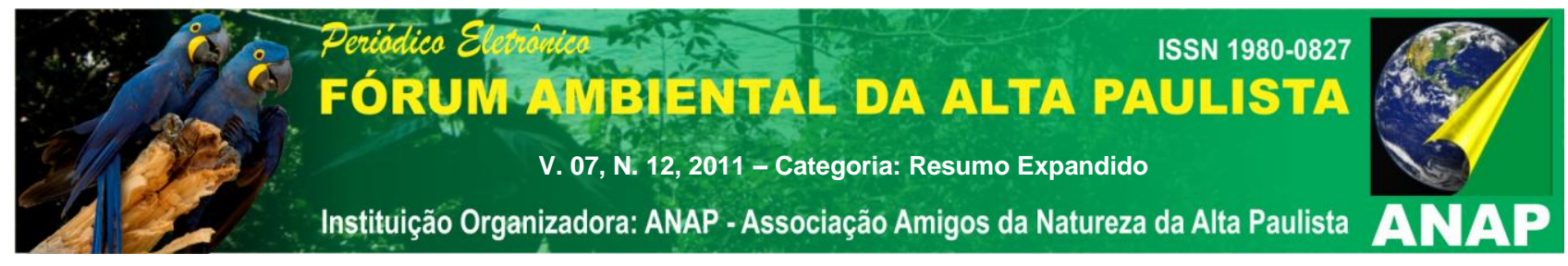

No aparelho jar test o tempo de mistura rápida a $120 \mathrm{rpm}$ foi de 60 segundos, 0 tempo de mistura lenta a $40 \mathrm{rpm}$ foi de 20 minutos e o tempo de sedimentação durou cerca de 15 a 30 minutos.

Posteriormente ao tratamento, analisou-se a remoção de DQO e de cor aparente. A determinação da cor aparente foi realizada com o auxílio do medidor de cor da marca HANNA $^{\circledR}$ modelo HI 93727, que utiliza o método platina cobalto, padrão para a medição da cor. A DQO foi determinada segundo a metodologia descrita pelo Standard Methods for the Examination for Water and Wastewater (APHA, 1998) e os equipamentos utilizados foram: reator de DQO da marca HANNA ${ }^{\circledR}$ modelo $\mathrm{HI} 839800$ para digestão das amostras, e espectrofotômetro da marca FEMTO ${ }^{\circledR}$ modelo 700 plus, para leitura de absorbância.

\section{RESULTADOS}

Os resultados da caracterização do lixiviado bruto quanto ao $\mathrm{pH}$, a cor aparente (mg PtCo. $\mathrm{L}^{-1}$ ) e a DQO $\left(\mathrm{mg} \mathrm{O}_{2} \cdot \mathrm{L}^{-1}\right)$ foram de 8,3; 2.665 e 1.562, respectivamente.

Devido ao $\mathrm{pH}$ mais elevado da amostra bruta pode-se classificar o lixiviado como sendo de aterro maduro. $\mathrm{O}$ valor de $\mathrm{pH}$ está dentro da faixa encontrada por Bassani (2010) que varia de 5 a 9, e se encontra um pouco abaixo dos encontrados por Nagashima (2009), que foram superiores a 8,4, inclusive.

É importante ressaltar que a cada ensaio mediu-se novamente $\mathrm{o} \mathrm{pH}$ do lixiviado bruto antes do ajuste de $\mathrm{pH}$ desejado para fins de tratamento, e a cor aparente. Os valores de $\mathrm{pH}$ não apresentaram variação, enquanto os de cor aparente variaram de 2.200 a $3.900 \mathrm{mg}$ de PtCo. $\mathrm{L}^{-1}$.

O valor de DQO do lixiviado bruto coletado variou de 1.210,67 a $2.144 \mathrm{mg}$ de $\mathrm{O}_{2} \cdot \mathrm{L}^{-1}$, sendo a média de $1.562,55$, valor relativamente alto que pode significar um potencial de recalcitrância do material.

Os ensaios de coagulação, floculação e sedimentação do lixiviado, utilizando as dosagens de 0,4;0,8 e 1,2 g/L de coagulante quitosana, em $\mathrm{pH}$ 3,0 apresentaram remoção de cor de aproximadamente 35; 47 e 50\%, respectivamente. Para o pH igual a 4,0 os resultados foram próximos de $65 ; 70$ e $43 \%$ e no pH 5,0 as eficiências de remoção de cor foram de aproximadamente 69; 73 e 77\%, respectivamente. Assim, a melhor 


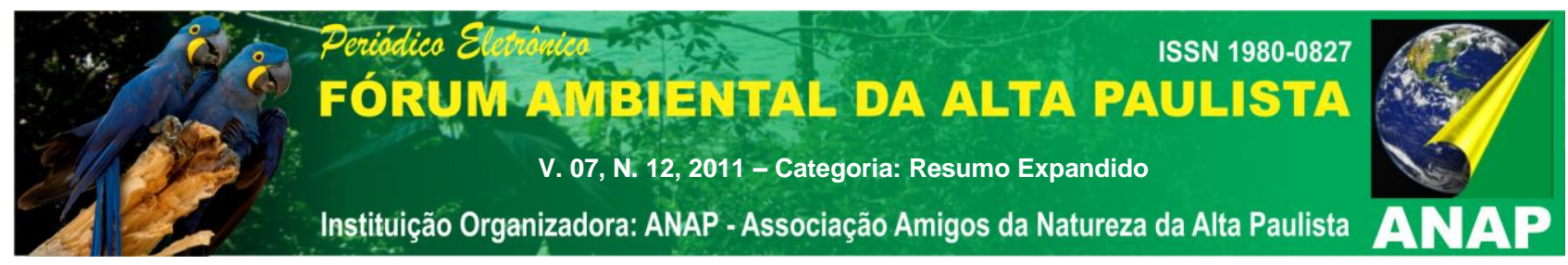

remoção de cor ocorreu no pH 5,0 (77,08\%), sendo que neste $\mathrm{pH}$ a remoção de cor aumentou em função do aumento da concentração de quitosana.

Os resultados de eficiência de remoção da DQO, utilizando as dosagens de 0,4; 0,8 e 1,2 $\mathrm{g} / \mathrm{L}$ de coagulante, para o $\mathrm{pH} 3,0$ foram de aproximadamente $7 ; 2$ e 1\%. Para 0 $\mathrm{pH} 4,0$ as eficiências de remoção de DQO foram próximas a $41 ; 27$ e $21 \%$. No pH 5,0 as eficiências de remoção foram de aproximadamente 9; 18 e 10\%, respectivamente.

Assim, observou-se uma boa remoção na concentração de $0,4 \mathrm{~g} / \mathrm{L}$ para $\circ \mathrm{pH} \mathrm{4,0}$ $(40,76 \%)$, porém este bom resultado não foi mantido nas concentrações e pHs seguintes.

Desta forma, pode-se dizer que a quitosana apresentou considerável remoção de cor, principalmente no pH 5,0, e que quando aplicada na remoção de DQO apresentou uma redução um pouco menor deste parâmetro, mas que foi significativa em termos da eliminação de matéria orgânica e que poderia ser aumentada com estratégias adicionais para a remoção deste parâmetro.

\section{CONSIDERAÇÕES FINAIS}

Os parâmetros qualitativos analisados permitem classificar o lixiviado do lixão de Presidente Prudente como alcalino, de cor não muito intensa e com características de aterro velho (baixa $\mathrm{DQO}$ e $\mathrm{pH}$ acima de 8,0 ).

O melhor resultado quanto à remoção de cor aparente foi de aproximadamente $77 \%$, que se deu na dosagem de $1,2 \mathrm{~g} / \mathrm{L}$ de quitosana em $\mathrm{pH} 5,0$.

A quitosana apresentou boa eficiência na remoção do parâmetro $\mathrm{DQO}$, sendo o melhor resultado de remoção de 40,76\% na dosagem de $0,4 \mathrm{~g} / \mathrm{L} \mathrm{em} \mathrm{pH} \mathrm{4,0.}$

Assim, pode-se dizer que a quitosana apresentou resultados satisfatórios e que poderiam ser empregados no tratamento de coagulação, floculação e sedimentação do chorume em maior escala. Contudo, ainda são necessários tratamentos adicionais para melhorar a eficácia do sistema de tratamento proposto.

\section{REFERÊNCIAS}


APHA - American Public Health Association. Standard methods for the examination for water and wastewater. 19th ed. Washington, D.C., 1995.

BASSANI, F. Monitoramento do lixiviado do aterro controlado de Maringá, Paraná, e avaliação da tratabilidade com coagulantes naturais, radiação ultravioleta (UV) e ozônio. Maringá, 2010. Dissertação (Mestrado em Engenharia Química). Universidade Estadual de Maringá, 2010.

KAWAMURA, Y., MITSUHASHI, M., TANIBE, H. Adsorção of Metal Ions on Polyaminated Highly Porous Chitosan Chelating Resin. Ind. Eng. Chem. Res., v. 32, n. 2, pp. 386-391, 1993.

KIMURA, I.Y. Remoção de Corantes Reativos Contendo Grupos Vinilsulfona e Triazina por Adsorção e Coagulação/Floculação com Quitosana. Florianópolis, 2001. Tese (Doutorado em Engenharia Química). Universidade Federal de Santa Catarina. Florianópolis, 2001.

GIRARDI, F. Tratamento de vinhaça utilizando coagulantes naturais. Maringá, 2009. Tese (Doutorado em Engenharia Química). Universidade Estadual de Maringá, 2009.

MADRONA, G. S. Estudo da extração/purificação do composto ativo da semente da Moringa oleifera lam e sua utilização no tratamento de água de abastecimento. Maringá, 2010. Tese (Doutorado em Engenharia Química). Universidade Estadual de Maringá, 2010.

NAGASHIMA, L.A. Monitoramento do lixiviado em lagoa de estabilização e estudo da aplicabilidade do reagente Fenton e do coagulante tanino como formas de tratamento. Maringá, 2009. Tese (Doutorado em Engenharia Química). Universidade Estadual de Maringá, 2009. 